THE KURUME MEDICAL JOURNAL

Vol.26, No.2, p. 135-143, 1979

\title{
TOTAL HIP REPLACEMENT OPERATION WITH ACETABULOPLASTY
}

\author{
SEIKEI MIYAGI AND HIROSHI HIEDA \\ Department of Orthopedic Surgery, Kurume University School of Medicine, \\ Kurume, 830, Japan
}

Received for publication February 28, 1979

\begin{abstract}
Fifty eight total replacement operations were carried out on the hips with deficient acetabulum. The acetabulum was reconstructed by bone grafting. The active exercise was started one week after the operation and the partial weight bearing was allowed 3 to 4 weeks. Remodelling of the reconstructed acetabulum was completed in one and a half years after operation, and the stable fixation of the prosthetic socket was secured without one loosening in all cases.
\end{abstract}

\section{INTRODUCTION}

Since 1952, 402 cases of coxarthrosis have been subjected to the operation at the Department of Orthopedic Surgery, Kurume University Hospital. Primary coxarthrosis were only 24 cases, and secondary were 378 , of which 345 were caused by congenital hypoplasia, subluxation and disclocation of the hip joint. As the acetabulum in congenital dysplasia is steep and shallow, it is a very important problem to fix the prosthetic socket stably to the deficient acetabulum in the total hip replacement operation. The authors present their experiences and the counter-measures for the loosening of the prosthetic socket.

\section{MATERIALS AND RESULTS}

The total hip replacement operation was started at our department in 1971, and has been carried out on 126 hips up to date. Among our early cases, one earlier and two late occurrences of loosening of the socket were encountered, out of which two cases are presented here.

A 57-year-old female patient was operated on with McKee-Farrar's endoprosthesis and the loosening of the socket occurred suddenly 2 weeks after operation (Fig. 1). The socket was cemented after acetabuloplasty using iliac bone graft. The clinical course was favourable and the result was excellent 3 years and 3 months after the operation (Fig. 2).

In another female patient aged 54 years with severe dislocation coxarthrosis, loosening of thesocket occurred 3 years after operation (Fig. 3). The socket was cemented after acetabuloplasty using iliac bone, and the result was excellent 2 years after the operation (Fig. 4).

We have operated on of 58 cases with bone graft for reconstructing the deficient acetabulum and no loosening of the prosthetic socket was encountered with satisfactory results up to date.

* This paper was read at SICOT Congress Kyoto, 1978. 


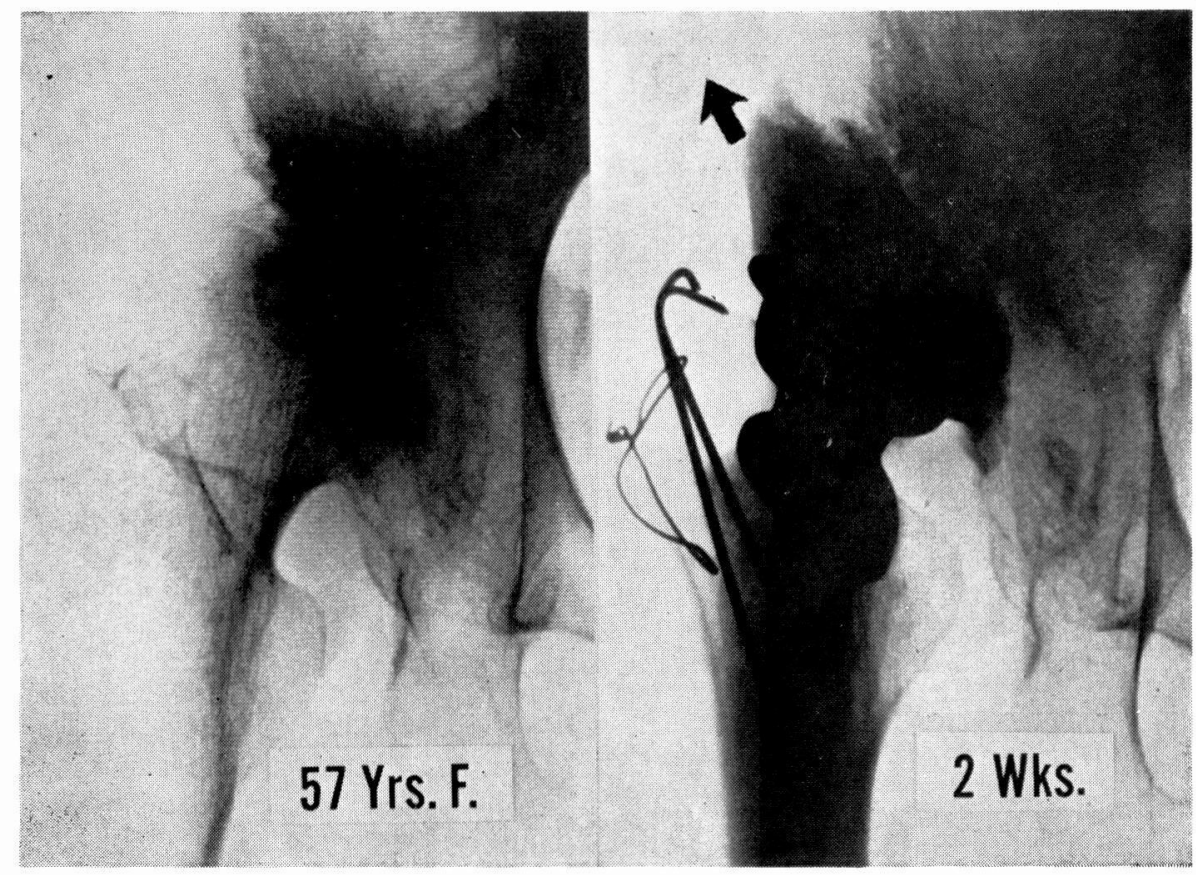

Fig. 1.

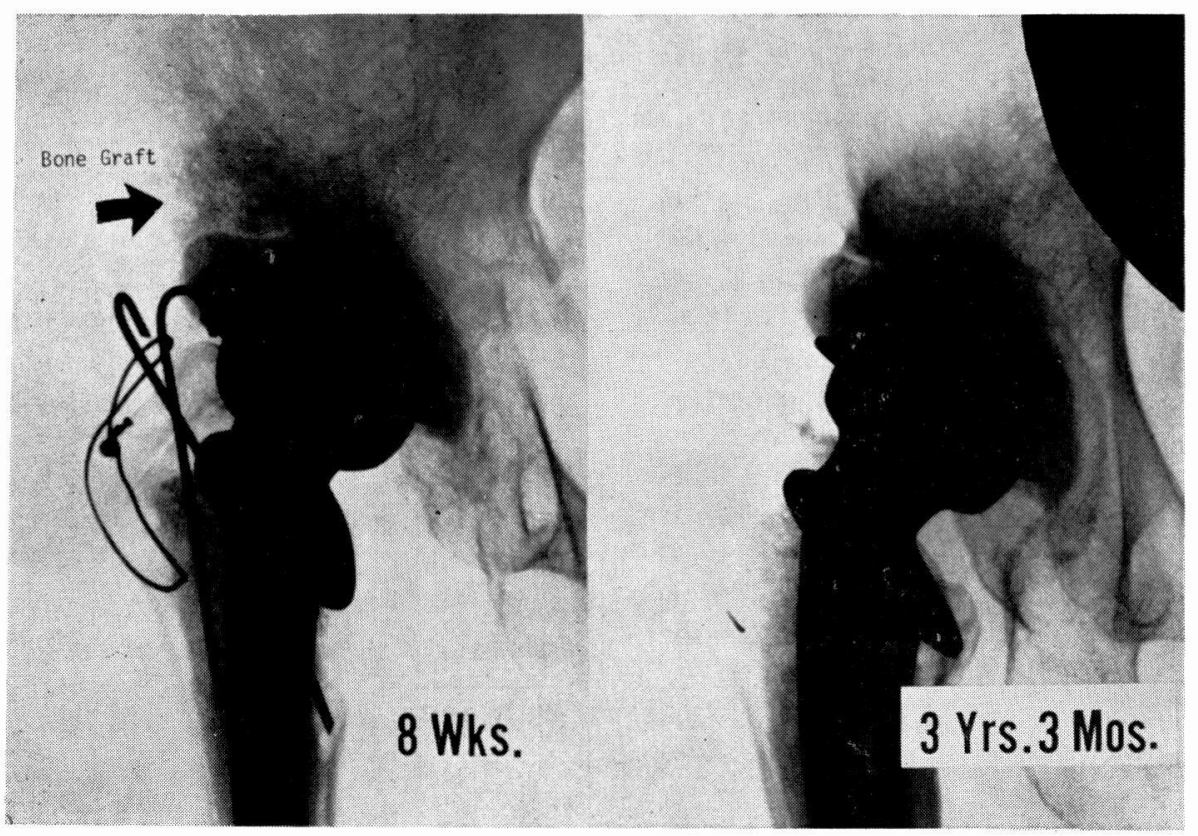

Fig. 2. 


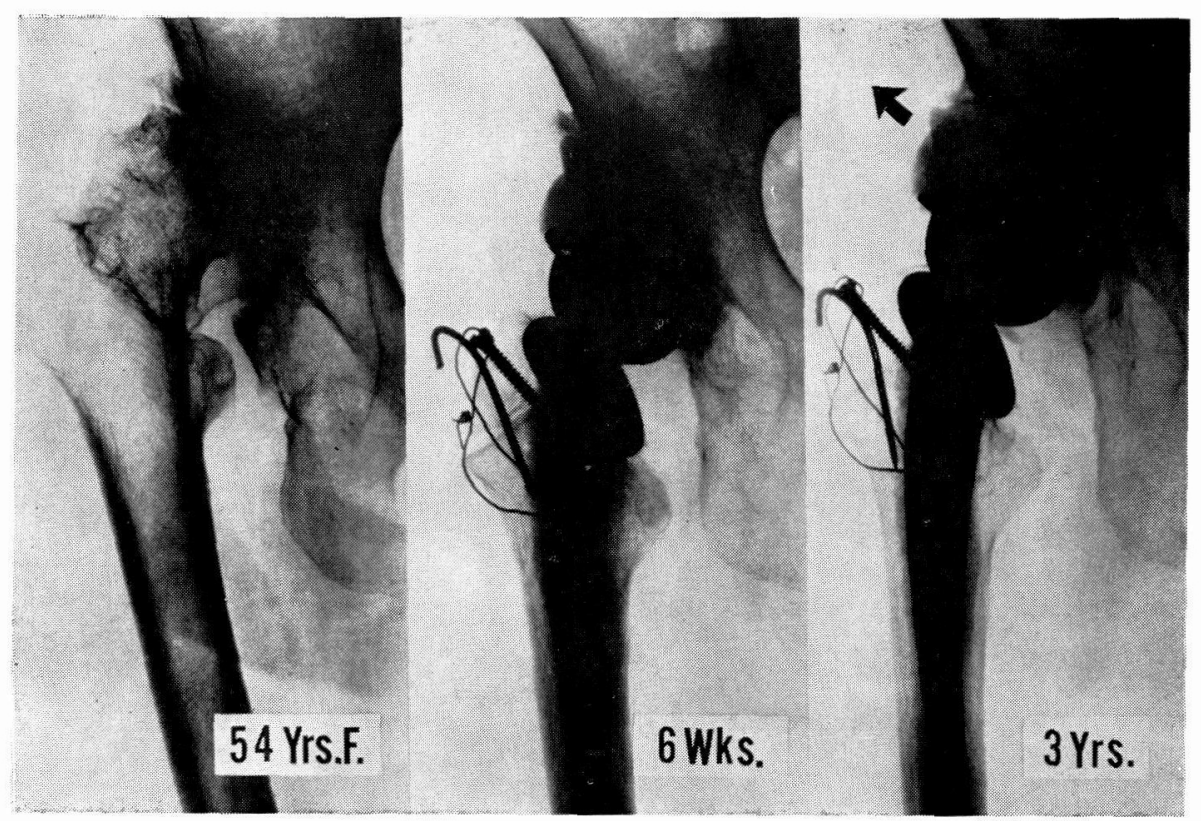

Fig. 3 .

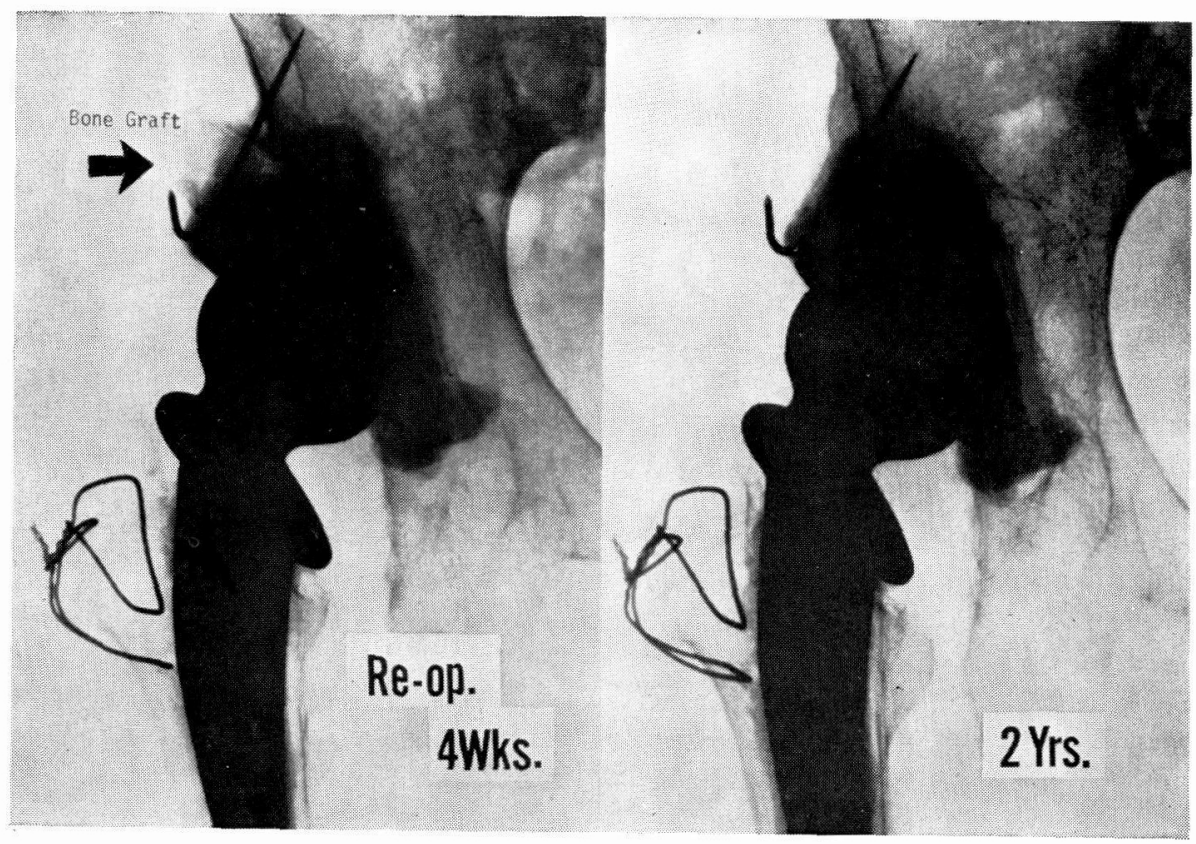

Fig. 4. 


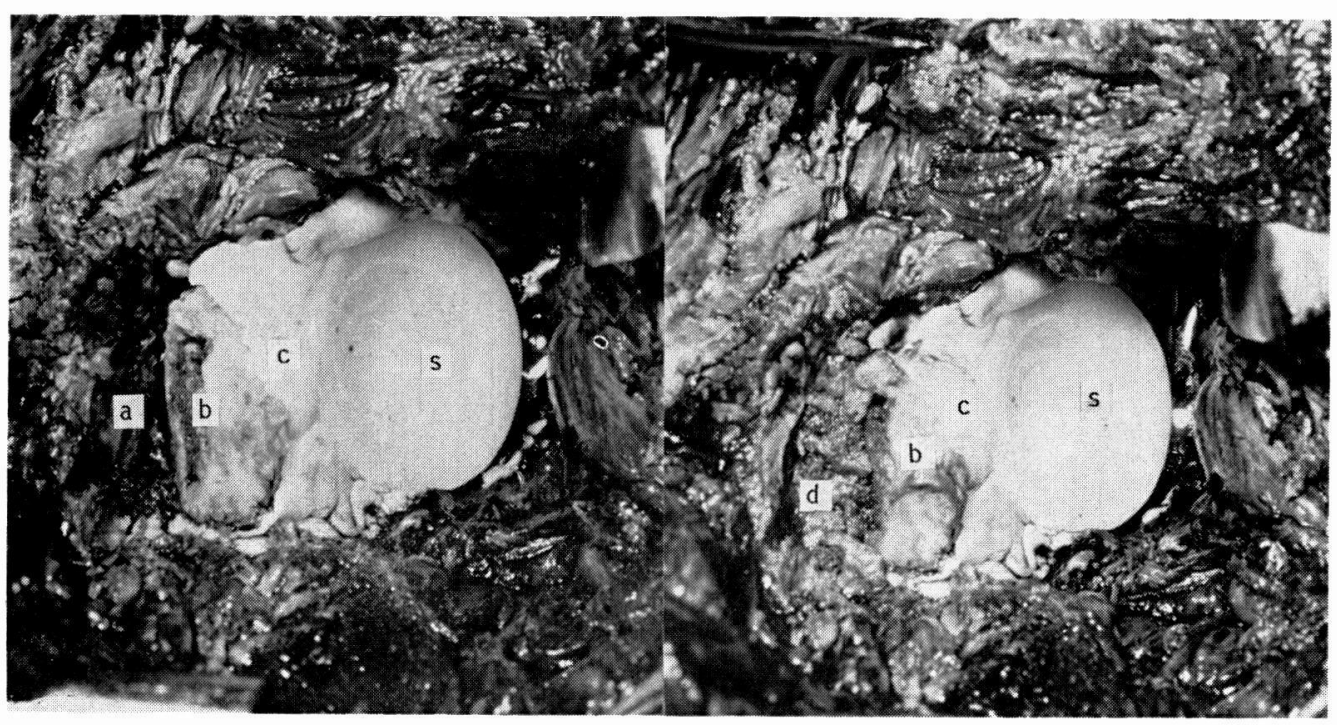

Fig. 5. a : acetabulum

b : bone graft

c : bone cement

$\mathrm{d}$ : chip bones

s : socket

\section{OPERATIVE METHOD}

We employ a postero-lateral approach and an osteotomy of the trochanter is carried out. After retracting the gluteal muscles caudally, joint capsule is resected. The femoral head is dislocated by flexion, adduction and external rotation of the hip. After cutting off the femoral neck, the remaining joint capsule is completely resected. Central osteophyte is removed and a floor of the original acetabular fossa is exposed. The acetabulum is deepend with a duty drill remaiming the floor of the acetabular fossa. After anchor holes are made, the prosthetic socket is tested to place as near as possible to its original position. If a gap remains between upper part of the acetabulum and superior border of the prosthetic socket, or superior border of the prosthetic socket is not covered by bone, a shelf is made with bone graft. Iliac bone, the resected femoral head and neck, cancellous bone of the trochanter, bone mash produced by reaming of the acetabulum and/or osteophytes are used as bone grafts (Fig. 5). In the early stage of our experiences, a main bone graft was fixed to the acetabular wall with Kirschner's wire, but recently, it is held with a finger tip during polimerization of bone cement. The other procedures are not different from the usual ways.

After operation, the leg is placed in a slightly abducted position under skin traction for 3 to 4 weeks and the patient is allowed to walk without weight bearing. Weight bearing is allowed routinely 3 to 4 months after the operation.

An interesting case which was recently operated on is shown here :

A 53-year-old female patient underwent endoprosthesis operation on her both hips 26 years ago. After the operations, limping was not improved, and she was unable to walk without crutches and was compelled to indoor life. She became troubled with hip pain day 
and night for 6 months. On examination, she was ab!e hardly to walk without crutches, and limping was marked. $\mathrm{X}$-ray findings were miserab!e, showing deterioration of the hips with dislocation and a breakage of the left endoprosthesis (Fig. 6-A). At first, the left hip was operated on, and the right hip 3 months later by the method as described above. After the deficient acetabular roof was reconstructed by using the resected femoral neck and chip bones from osteophytes, the remaining gap was packed with the bone mash. The stable acetabulum was reconstructed $4 \mathrm{~cm}$. caudally from the preoperative false one. The patient is now under after-treatment and the clinical course is favourable (Fig. 6-B).

Remodelling of the reconstructed acetabulum :

At the total replacement operation

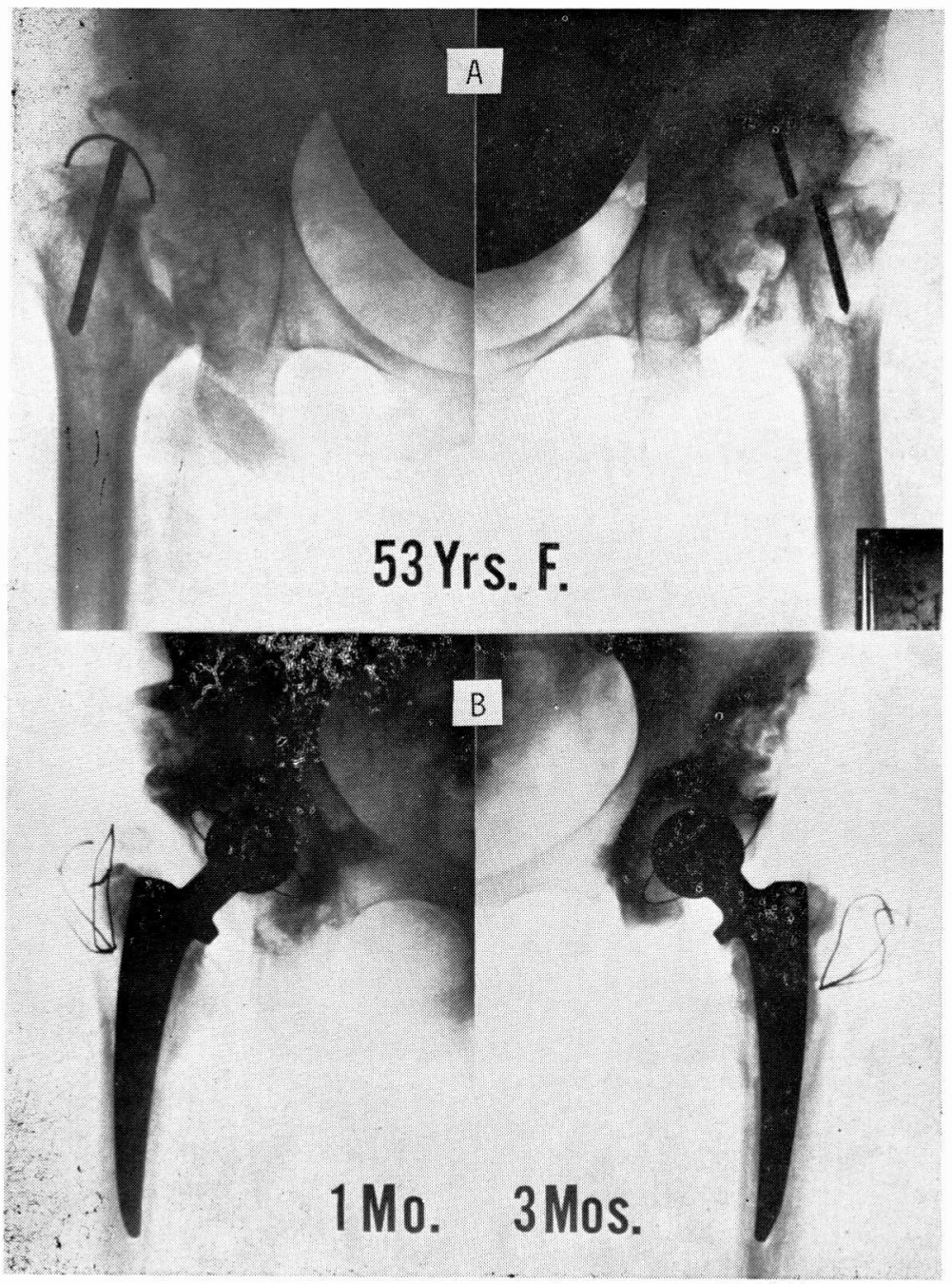

Fig. 6. 
for the hip with deficient acetabulm, we have reconstructed the acetabulm by using bone grafts. It is, therefore, very important and interesting to know the fate of the grafted bones and a remodelling of the acetabulm reconst- ructed.

In some of our early cases, in which the acetabulum was not reamed deeply enough, the bone graft protruded from the acetabular rim. In a female patient aged 55 years, a tapering of the pro-

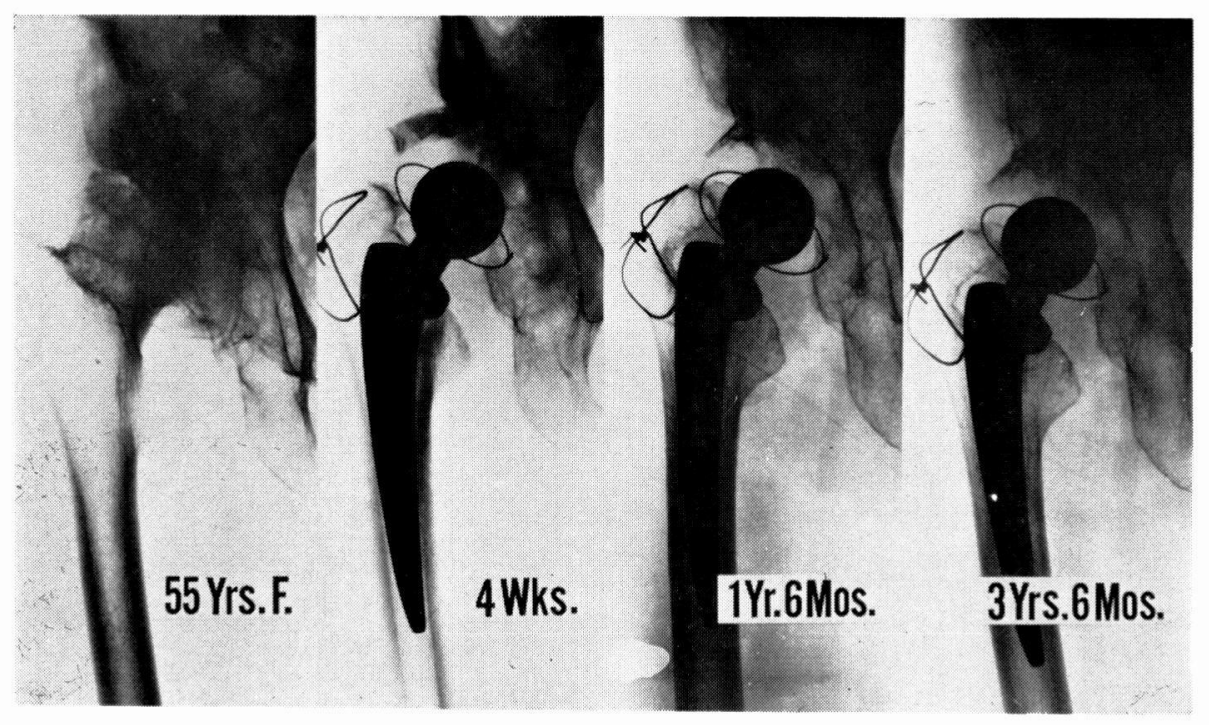

Fig. 7.

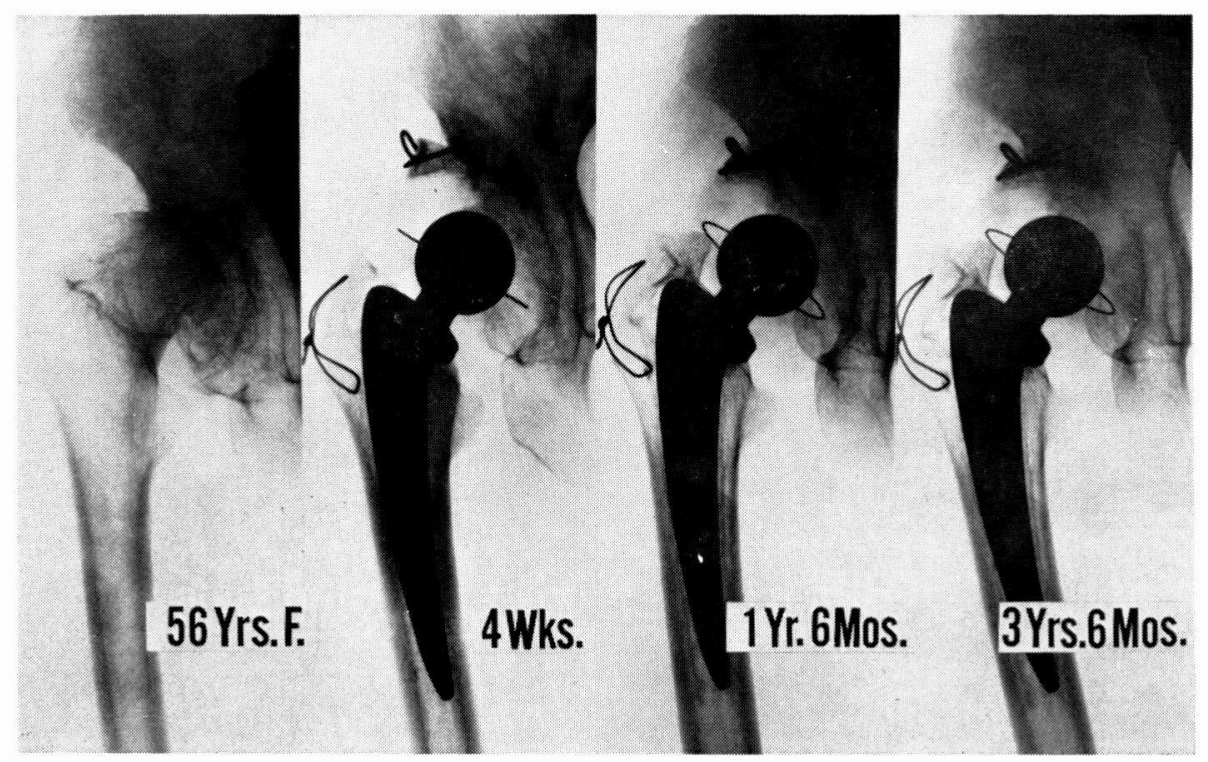

Fig. 8. 
truded bone graft was detected one and a half years after operation, but no absorption occurred thereafter (Fig. 7). In another female patient aged 56 years, the protruded bone graft, which was fixed with Kirschner's wire, remained stably 2 and a half years after operation (Fig. 8).
In the majority of cases, the outer part of bone graft protruded slightly beyond the acetabular rim, or the bone grafts, were located entirely inside of the acetabular rim. In a 62 -year-old female patient, the bone grafts located slightly beyond the acetabular rim seemed to unite with the acetabular

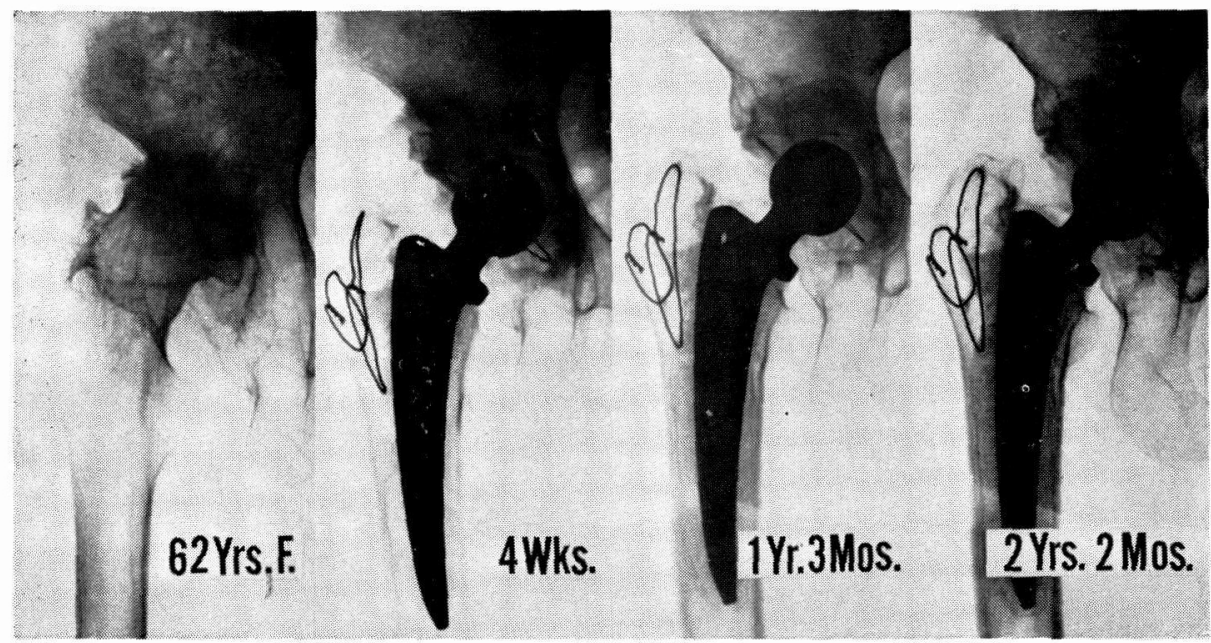

Fig. 9.

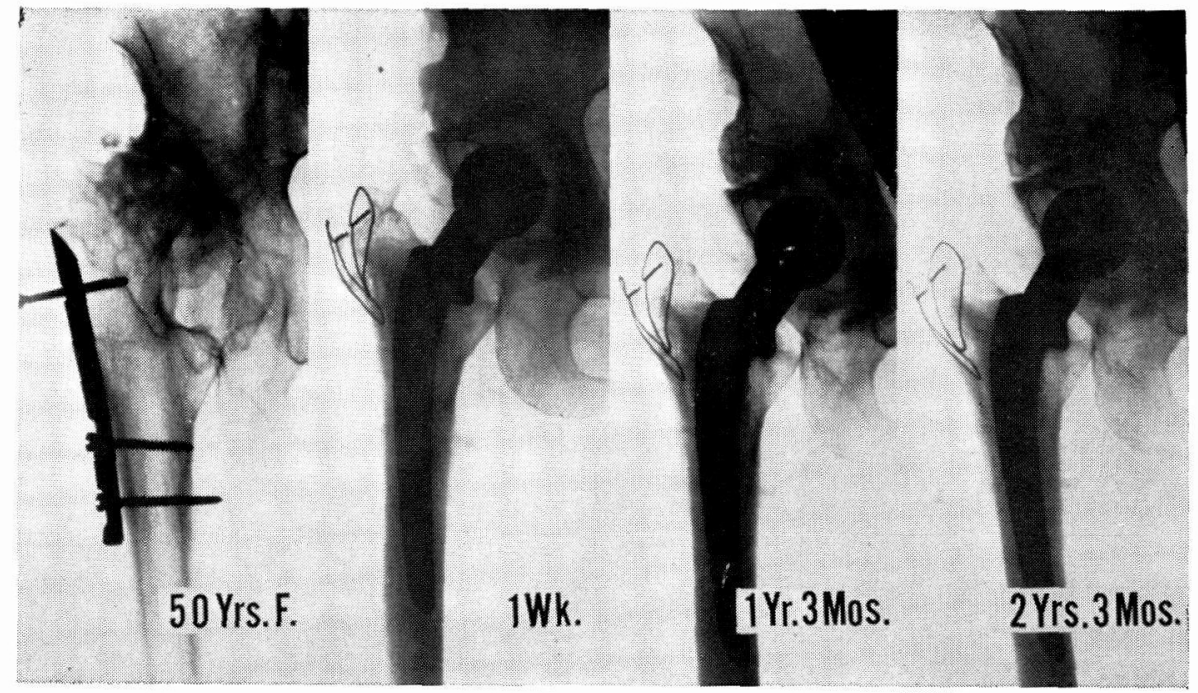

Fig. 10. 
wall in 4 weeks, and the stable acetabulum was reconstructed one year and 3 months after operation (Fig. 9). In another 50-year-o'd female patient with severe subluxated coxarthrosis operated on previously by valgus osteotomy, the bone grafts united with the acetabular wall in 11 weeks and the remolelling to the stable acetabulum was completed in one year and 3 months after operation (Fig. 10).

\section{DISCUSSION}

At the total replacement operation for the hip with the deficient, acetabulum, a wide space remains usually between the upper part of acetabular wall and the superior border of the prosthetic socket, and a fixation of the socket becomes bio-mechanically unstable because of shearing and rotationary forces acting between the bone cement and the underlying bone surface as suggested by Charnley and Tager.

Special sockets or operative procedures to secure the firm fixation of the socket have been reported by many authors.

Small sockets with an external diameter of 40 or $38.5 \mathrm{~mm}$ are used by Charnley, Kinoshita, Kobayashi, Mau, Nagai and Tronzo. Ryo and Kashiwagi, of Kobe University, designed a Kobe dysplastic hip prosthesis for the steep acetabulum. Nagai and others fixed the upper part of the bone cement by screw to the acetabular wall, and Mau made small anchor holes in an cblique direction into the acetabulum.

On the other hand, many authors attempted to reconstruct the deficient acetabulum to create a bony shelf above the acetabulum. Charnley applied grafts of bone obtained from the resected femoral head or bone-pastes from the reaming of the acetabulm. Dunn, Harris, Kinoshita, Kobayashi, Kotani, Nagai, Postel and Tronzo also employed a bone grafting by using the resected femoral neck or head, and many of them fixed the bone graft to the acetabular wall by screw. Reconstructing the acetabulum, Chiari and Kotani performed pelvic osteotomy, and Kobayashi, Kotani and Nagai recommended a shelf opertion.

After these operations, the patients are in general allowed to walk in 3 to 4 months, while Charnley advised full weight bearing in 5 weeks following 3 weeks of splint fixation in an abducted position of the hip.

In order to fix the prosthetic socket in cases with the deficient acetabulum, we reconstructed the acetabulum by bone grafting. The bone grafts were taken from the iliac crest, the resected femoral head or neck and the cancellous bone of the trochanter. Chip bones from osteophyte and the bone mashes produced by reaming of the acetabulum were also used. While the bone graft has been fixed with Kirschner's wire in the early stage of our experiences, it is held recently with a finger tip during polimerization of the bone cement.

After this operation, the active exercise is started in a week, partial weight bearing in arround 3 to 4 weeks, and full weight bearing in 3 to 4 months. Remodelling of the reconstructed acetabulum is completed at the latest by one and a half years, and the stable fixation of the prosthetic socket is secured.

Our operative proceciure described above is so simple and able to be performed without special device and instrument, and is thought to be encouraging for the treatment of hypoplastic coxarthrosis. 


\section{REFERENCES}

Charnley, J. et al. (1973). Low-Fraction Arthroplasty in Congenital Subluxation of the Hip. Clin. Orthop. and Related Research. 91, 98-113.

ChARnLEy, J. (1973). Arthroplasty of the Hip: A New Operation. Clin. Orthop. and Related Research. 95, 4-8.

ChIARI, K. (1973). A Contribution to the Surgical Technique of Total Arthroplasty of the Hip in Extreme Dysplasia. Arthroplasty of the Hip (Edited by George Chapchal) Georg Thieme. Stuttgartp. 83.

DunN, H. K. et al. (1976). Total Hip Reconstruction in Chronically Dislocated Hips. J. Bone Jt. Surg. 58-A, 6 ; 838-845.

HARRIS, W. H. et al. (1977). Total Hip Replacement and Femoral-Head Bone-Grafting for Severe Acetabular Deficiency in Adults. J. Bone Jt. Surg. 59-A, 6; 752-759.

KINoshitA, I. et al. (1976). Indication of Total Hip Replacement for High Dislocated Osteoarthritis. Clin. Orthop. Surg. (Japanese) 11,$11 ; 1014-1018$.

Kobayashi, M. et al. (1978). Total Hip Replacement Operation for Hypoplastic Acetabulum and Disloca ed Hip. Cent. Jap. Orthop. Traumat. (Japanese) 21, 1; 63-65.

Kotani, T. et al. (1974). Study on Total Hip Replacement Operation for Coxarthrosis. Clin. Orthop. Surg. (Japanese) 9, 7;591601.

MAU, H. (1973). Total Endoprosthesis in Old Congenital Dislocation of the Hip. Arthroplasty of the Hip (Edited by George Chapchal) Georg Thieme, Stuttgart. p. 86-87.

MilleR, A. J. (1972). Late Fracture of the Acetabulum after Total Hip Replacement. J. Bone Jt. Surg., 54-B, 4;600-606.

MIYAGI, S. et al. (1975). Total Hip. Replacement Operation for Steep Acetabulum. Orthopedics and Traumatology (Japanese), 24,$3 ; 385-388$.
MiYAGI, S. (1977). Evolution of Treatments for Coxarthrosis. J. Kurume Med. (Japanese). 40, $12 ; 1883-1907$.

NAGAI, J. (1976). Indication of Total Hip Replacement Operation with Charnley's Endoprosthesis. Operation (Japanese) 30, $9 ; 929-$ 935.

NAGAI, J. (1976). Total Hip Replacement Operation for Hypoplastic Acetabulum. J. Jap. Orthop. Ass. 50, 9 ; 719-726.

NaGAI, J. (1977). Charnley Type of Total Hip. Clin. Orthop. Surg. (Japanese) 12, 1;2-5.

Postel, M. (1973). Total Hip Prosthesis in Old C.D.H. in Adults. J. Jap. Orthop. Ass. 47,$12 ; 1042-1044$.

Ryo, F. et al. (1973). Total Hip Replacement Operation for Secondary Co- $\mathrm{x}$-arthrosis. Cent. Jap. Orthop. Traumat. (Japanese). 16,$3 ; 674-676$.

Ryo, F. et al. (1974). New Total Hip Prosthesis for Hypoplastic Acetabulum. J. Jap. Orthop. Ass. (Japanese). 48, $10 ; 662-663$.

Ryo, F. et al. (1976). Kobe Dysplastic Hip Prosthesis. J. Jap. Orthop. Ass. (Japanese). 50, $3 ; 135-156$.

Ryo, F. et al. (1976). Total Hip Replacement Operation for Hypoplastic Hip. J. Jap. Orthop. Ass. (Japanese). 50, 9; 710-712.

Ryo, F. et al. (1977). Kobe Dysplastic Prosthesis. Clin. Orthop. Surg. (Japanese). 12,$7 ; 628-631$.

Simon, R.R. et al. (1975). "Stition-Friction" of Total Hip Prostheses and Its Relationship to Loosening. J. Bone Jt. Surg. 57-A $2 ; 226-230$.

TäGER, K. H. (1977). Zum Problem der Pfannenauslockerung bei der Totalendoprosthese der Hüfte. Arch. orthop. Unfall-Chir. 87, $1 ; 39-49$.

Tronzo, R. G. et al. (1975). Anatomic Restoration of Congenital Hip Dysplasia in Adulthood by Total Hip Displacement. Clin. Orthop. and Related Research. 106, 94-98. 